Jurnal Psikologi Teori dan Terapan

2016, Vol. 6, No. 2, 107-112, ISSN: 2087-1708

\title{
Pengaruh Pelatihan Otogenik Terhadap Penurunan Kecemasan Atlet Bulutangkis
}

\author{
Eva Nur Rachmaningdiah, Miftakhul Jannah \\ Program Studi Psikologi Universitas Negeri Surabaya
}

\begin{abstract}
The purpose of this study was to examine the effect of autogenic training on the decrease of anxiety among Badminton athletes. Autogenic training is a training focused on suggesting the athlete's specific part of body to get its sensations. This study used an experimental method with pretest-posttest control group design. The subject of this study were 12 athletes under 18 years old at Surabaya Hi-Qua Wima Badminton Association. Autogenic training treatment is given only in the experimental group. Data were obtained by using sport anxiety scale, adapted from Amir (2012) and developed from SAS (sport anxiety scale) and analyzed using Gain Score and Wilcoxon Test. The result showed significant score $=0.027,(p<0.05)$ it means, that the autogenic training is able to decrease the anxiety on badminton athletes after autogenic training was given. In addition, the decrease in the anxiety of badminton athletes can be seen from gain score in both groups, the experiment group had an lower value of gain score than control group $(34,67<43,33)$, it means that the autogenic training is able to decrease the anxiety of badminton athletes. The result shows that the hypothesis of this study that "there is the effect of autogenic training on the decrease anxiety badminton athletes" can be accepted.
\end{abstract}

Keywords: Autogenic training, anxiety, athlete

\begin{abstract}
Abstrak: Penelitian ini bertujuan untuk menguji efek dari pelatihan otogenik terhadap penurunan kecemasan atlet. Pelatihan otogenik adalah pelatihan yang dilakukan dengan cara memfokuskan pada area tubuh tertentu dengan memberikan sugesti kepada atlet agar merasakan sensasi dari sugesti tersebut. Penelitian ini menggunakan metode penelitian eksperimen dengan pretest-posttest control group design. Subjek penelitian adalah atlet bulutangkis PB. Hi-Qua Wima Surabaya sebanyak 12 orang yang berusia dibawah 18 tahun. Perlakuan berupa pelatihan otogenik diberikan hanya pada kelompok ekperimen. Data diperoleh menggunakan skala kecemasan olahraga yang dikembangkan dari SAS (Sport Anxiety Scale). Analisis data yang digunakan dalam penelitian ini adalah Uji Wilcoxon dan Gain score. Berdasarkan hasil analisis Uji Wilcoxon diperoleh nilai Sig. $=0.027,(\mathrm{p}<0.05)$ hal tersebut berarti ada penurunan kecemasan atlet bulutangkis setelah diberikan pelatihan otogenik. Selain itu, penurunan kecemasan atlet bulutangkis dapat dilihat dari nilai gain score pada kedua kelompok, nilai gain score pada kelompok eksperimen lebih rendah daripada kelompok kontrol $(34,67<43,33)$, artinya pelatihan otogenik berpengaruh terhadap penurunan kecemasan atlet bulutangkis. Hasil analisis tersebut menunjukkan bahwa hipotesis "ada pengaruh pelatihan otogenik terhadap penurunan kecemasan pada atlet bulutangkis" diterima.
\end{abstract}

Kata kunci: Pelatihan Otogenik, kecemasan, atlet

Korespondensi tentang artikel ini dapat dialamatkan pada Eva Nur Rachmaningdiah melalui email:evaevo02@gmail.com. 
Olahraga berarti gerak badan untuk menguatkan dan menyehatkan tubuh. Wann (1997) menyatakan bahwa olahraga adalah aktivitas yang melibatkan power dan skill, kompetisi, strategi, pencapaian pribadi (pendapatan) dari pelaku atau orang lain, meliputi olahraga terorganisasi dan olahraga rekreasional, dan olahraga sebagai hiburan.

Bulutangkis sebagai salah satu cabang olahraga permainan yang popular dan digemari oleh masyarakat Indonesia, dengan memasyarakatkannya bulutangkis tersebut maka usaha-usaha untuk menuju prestasi bulutangkis harus secara terusmenerus digalakkan dan ditingkatkan. Melalui olahraga ini nama Indonesia dikenal di dunia internasional (Adisasmito, 2007).

Menurut Satiadarma (2000), atlet adalah individu yang unik, mereka memiliki bakat tersendiri, pola perilaku dan kepribadian tersendiri, serta latar belakang kehidupan yang mempengaruhi dirinya secara spesifik. Atlet adalah orang yang melakukan latihan agar mendapatkan kekuatan badan, daya tahan, kecepatan, kelincahan, keseimbangan, kelenturan dan kekuatan dalam mempersiapkan diri jauhjauh sebelum pertandingan dimulai.

Prestasi yang selama ini diraih oleh para atlet tentunya melalui perjuangan dan proses yang berat. Ada beberapa faktor yang mempengaruhi prestasi atlet, baik dari segi teknik, taktik, mental/psikis dan kondisi fisik lainnya (Adisasmito, 2007). Kondisi psikologis merupakan suatu kondisi yang berkontribusi terhadap pelatihan atlet. Faktor psikologis merupakan struktur dan fungsi aspek psikis, seperti kecemasan, motivasi, emosi, percaya diri dan beberapa aspek psikologis lainnya, oleh karena itu penelitian ini berfokus pada faktor psikologis.

Atlet yang tidak sukses mewujudkan kemampuan optimalnya disebabkan oleh rasa takut gagal yang berlebihan. Hal ini dapat dilihat ketika pertandingan bergulir, sering terlihat seorang atlet yang sudah mempunyai kemampuan fisik yang baik, teknik yang bagus, dan sudah dibekali berbagai taktik, tetapi tidak dapat mewujudkannya dengan baik di arena pertandingan/perlombaan, dan akhirnya mengalami kekalahan. Hidayat (2012) mengatakan bahwa beberapa tahun terakhir prestasi bulutangkis Indonesia merosot jauh jika dibandingkan dengan prestasi sebelumnya.

Amir (2004) menjelaskan bahwa kecemasan yang timbul saat akan menghadapi pertandingan disebabkan karena atlet banyak memikirkan akibatakibat yang akan diterimanya apabila mengalami kegagalan atau kalah dalam pertandingan. Kecemasan juga muncul akibat memikirkan hal-hal yang tidak dikehendaki akan terjadi, meliputi atlet tampil buruk, lawannya dipandang demikian superior, dan atlet mengalami kekalahan (Satiadarma, 2000).

Berbagai hasil survey dan pengamatan di lapangan saat perlombaan tidak sedikit atlet yang mengalami kecemasan ketika dalam perlombaan sehingga merugikan penampilannya, karena sedikit atlet yang berlatih khusus untuk menurunkan kecemasan mereka sebelum perlombaan. Cox (2002) menyatakan pelatihan untuk menurunkan kecemasan bagi atlet adalah proses yang ditujukan kepada atlet untuk mengajarkan/melatih bagaimana cara membatasi dan melebarkan fokus perhatian serta untuk mengendalikan pikiran.

Kecemasan tidak selalu merugikan yang mengakibatkan kekalahan dalam perlombaan, karena pada dasarnya rasa cemas berfungsi sebagai mekanisme kontrol terhadap diri untuk tetap waspada terhadap apa yang akan terjadi. Spielberger (Gunarsa, 2008) membagi kecemasan menjadi dua, yaitu state anxiety dan trait anxiety. Trait anxiety adalah level kecemasan yang secara alamiah dimiliki oleh seseorang. Pada trait anxiety ini tingkat kecemasan menjadi bagian dari kepribadian yang melekat pada masingmasing atlet. Faktor individu pertama yang 
sangat mempengaruhi tingkat kecemasan seorang atlet adalah kondisi trait anxietynya.

Speilberg (dalam Cox, 2002) mengatakan bahwa trait anxiety mengacu pada perbedaan individu yang cenderung stabil dalam tingkatan kecemasannya. Hal itu berarti perbedaan antara orang dalam kecenderungan untuk mempersepsikan situasi stres sebagai bahaya atau mengancam dan untuk merespon situasi tersebut dengan kenaikan tingkat state anxiety. Trait anxiety mencerminkan perbedaan individu dalam jumlah dan kekuatan pada saat terjadi keadaan yang dipersepsi menimbulkan kecemasan yang pernah terjadi di masa lalu. Kecemasan dapat dilatih dan dikontrol dengan berbagai cara yang bertujuan untuk menurunkan kecemasan sehingga prestasi yang selama ini diinginkan dapat diraih.

Pelatihan yang digunakan pada penelitian ini adalah pelatihan otogenik. Pelatihan otogenik (autogenic training) adalah latihan dilakukan dengan memfokuskan pada area tubuh khusus secara bersamaan secara mental mengulang susunan kalimat sugestif tertentu. Pelaksanaan metode ini dilakukan melalui kontrol terhadap sistem saraf otonomi (Dalloway, 1993). Pelatihan Otogenik adalah salah satu teknik yang paling efektif untuk mengatasi stress atau kecemasan seseorang dalam menghadapi suatu masalah. Dalam pelatihan ini atlet memberikan sugestif tertentu pada bagian tubuh sehingga menghasilkan sensasi tertentu yang dirasakan dalam proses pelatihan.

\section{Metode}

Penelitian ini menggunakan rancangan eksperimen, desain eksperimen yang digunakan dalam penelitian ini adalah pretest-posttest control group design. Keunggulan dari desain ini yaitu proactive history yang berarti bahwa pretest menginformasikan kemampuan awal para subjek sebelum dilakukan penelitian.

Tabel 1. Proactive History KE dan KK

\begin{tabular}{cccc}
\hline \multicolumn{3}{c}{ Pretest } \\
\hline S & $\begin{array}{c}\text { Kelompok } \\
\text { Eksperimen }\end{array}$ & S & $\begin{array}{c}\text { Kelompok } \\
\text { Kontrol }\end{array}$ \\
\hline FL & 33 & MA & 44 \\
AS & 46 & KB & 47 \\
PS & 34 & MS & 53 \\
IIH & 51 & J & 40 \\
AB & 45 & YS & 28 \\
GT & 49 & DA & 46 \\
\hline Rata & 43 & Rata- & 43 \\
-rata & 43 & rata & \\
\hline
\end{tabular}

dimana seluruh populasi digunakan sebagai subjek penelitian. Populasi dalam penelitian ini adalah atlet bulutangkis Persatuan Bulutangkis (PB) Hi-Qua Wina Surabaya yang berjumlah 12 orang.

Instrumen penelitian yang digunakan adalah skala kecemasan olahraga yang diadaptasi dari Amir (2012) yang dikembangkan dari SAS (Sport Anxiety Scale). Skala ini digunakan untuk mengukur tingkat kecemasan seorang atlet bulutangkis. Skor didapat melalui pretest dan posttes yaitu pemberian tes dilakukan selama dua kali dengan skala yang sama.

Teknik analisis data yang digunakan adalah statistik non parametrik karena tidak berdistribusi normal. Analisis data tes statistik non parametrik yang digunakan dalam penelitian ini adalah uji perangkat bertanda Wilcoxon (Wilcoxon Signed Rank Test) yaitu membandingkan antara sebelum dan sesudah diberi perlakuan. Uji Wilcoxon digunakan untuk menguji beda dua kelompok yang bersifat berpasangan atau dependen antara satu variabel dengan variabel yang lain. Perhitungan dalam penelitian ini akan menggunakan bantuan program komputer SPSS (Statistical Product and Service Solution) versi 21.0 for Windows. Selain itu, data juga diperoleh dengan selisih skor (gain score) antara skor pada waktu posttest dan pretest.

\section{Hasil}

Berdasarkan hasil pretest dan posttest yang dilakukan pada kelompok eksperimen 
dan kontrol, didapatkan data sebagai berikut:

Tabel 2. Deskripsi Data Penelitian Kelompok Eksperimen dan Kelompok Kontrol

\begin{tabular}{|c|c|c|c|c|c|c|c|}
\hline \multirow[b]{2}{*}{5} & \multicolumn{3}{|c|}{ Kelompok Eksperimen } & \multirow[b]{2}{*}{$S$} & \multicolumn{3}{|c|}{ Kelompok Kontrol } \\
\hline & Pretest & Posttest & $\begin{array}{l}\text { Gain } \\
\text { score }\end{array}$ & & Pretest & Posttest & $\begin{array}{l}\text { Gain } \\
\text { score }\end{array}$ \\
\hline FL & 33 & 28 & -5 & MA & 44 & 46 & 2 \\
\hline AS & 46 & 42 & -4 & $\mathrm{~KB}$ & 47 & 43 & -4 \\
\hline PS & 34 & 28 & -6 & MS & 53 & 55 & 2 \\
\hline $\mathrm{IIH}$ & 51 & 36 & -15 & $\mathrm{~J}$ & 40 & 42 & 2 \\
\hline $\mathrm{AB}$ & 45 & 35 & -10 & YS & 28 & 27 & -1 \\
\hline GT & 49 & 39 & -10 & DA & 46 & 47 & 1 \\
\hline $\begin{array}{l}\text { Rata } \\
\text {-rata }\end{array}$ & 43 & 34 & $-8,33$ & $\begin{array}{l}\text { Rata } \\
\text {-rata }\end{array}$ & 43 & 43,33 & 0,33 \\
\hline
\end{tabular}

Penelitian ini bertujuan untuk mengetahui pengaruh pelatihan otogenik dalam menurunkan kecemasan atlet bulutangkis. Berdasarkan hasil ordinal pairing terhadap kedua kelompok yaitu kelompok eksperimen dan kelompok kontrol, rata-rata kedua kelompok ini sama yaitu $\mathrm{X}_{\mathrm{KE}}=\mathrm{X}_{\mathrm{KK}}=43$ yang berarti kedua kelompok homogen. Hasil posttest pada kelompok kontrol memiliki skor 43,33, hal ini berarti tidak terdapat perbedaan secara signifikan. Hasil posttest pada kelompok eksperimen menunjukkan skor sebesar 34,67, hal ini berarti bahwa terjadi perbedaan skor secara signifikan sehingga terjadi penurunan kecemasan yang terjadi pada kelompok eksperimen.

Hasil pengujian hipotesis dengan menggunakan uji perangkat bertanda Wilcoxon (Wilcoxon Signed Ranking Test) menujukkan bahwa ada penurunan tingkat kecemasan pada kelompok eksperimen setelah diberikan pelatihan otogenik. Hal ini dapat dilihat bahwa kelompok eksperimen memiliki skor signifikansi sebesar 0.027 , apabila dibandingkan dengan nilai probalitas sebesar 0.05 maka nilai signifikansinya lebih kecil dari nilai probabilitas.

Data berdasarkan perolehan selisih rata-rata skor (gain score) hasil posttest kelompok eksperimen mempunyai penurunan rata-rata sebesar $-8,33$ sedangkan pada kelompok kontrol mempunyai kenaikan rata-rata sebesar 0,33 . Perubahan rata-rata kelompok kontrol tidak berbeda secara signifikan, sedangkan perubahan rata-rata pada kelompok eksperimen berbeda secara signifikan, sehingga dapat disimpulkan bahwa pelatihan otogenik dapat menurunkan kecemasan pada atlet bulutangkis.

\section{Pembahasan}

Berdasarkan hasil penelitian ini pelatihan otogenik mampu menurunkan kecemasan atlet pada kelompok eksperimen, hal ini sesuai dengan Luthe (2000) yang menyatakan bahwa di bidang olahraga, berbagai laporan menunjukkan bahwa latihan teratur metode pelatihan otogenik mengarah pada kinerja yang lebih baik dengan meningkatkan reaktivitas dan koordinasi, daya tahan yang lebih baik, penyembuhan lebih cepat, dan pengurangan atau penghapusan gangguan psychoreactive yang cenderung terjadi sebelum turnamen penting.

Seorang atlet yang pada dasarnya memiliki kecemasan bawaan (trait anxiety) yang tinggi, maka manifestasi kecemasannya akan selalu berlebihan dan mendominasi aspek psikisnya. Hal ini merupakan kendala yang serius bagi atlet tersebut untuk dapat berpenampilan baik saat mengikuti pertandingan (Gunarsa, 2008). Atlet pada kelompok eksperimen cenderung memiliki trait anxiety yang agak tinggi dapat menurunkan kecemasannya menjadi agak rendah karena mendapatkan pelatihan otogenik, sehingga mereka dapat mempersepsikan suatu kejadian sebagai hal yang baik dan dapat terkendali.

Seorang atlet akan mempersepsikan pertandingan yang ia hadapi sebagai suatu situasi yang penuh ancaman dan menimbulkan kecemasan tinggi pada dirinya, apabila atlet tersebut memiliki kecemasan bawaan yang tinggi. Kecemasan bawaan ini relatif menetap dan merupakan bagian dari kepribadian suatu 
individu yang akan mempengaruhinya dalam suatu keadaan tertentu (Satiadarma, 2000).

Hal-hal lain yang dapat menurunkan kecemasan pada penelitian ini adalah dapat dijelaskan sebagai berikut.

Keefektifan pelatihan. Pelatihan mental akan efektif apabila dilakukan 4 kali pertemuan dalam satu minggu (Satiadarma, 2000). Pada penelitian ini pelatihan otogenik diberikan kepada atlet bulutangkis selama 4 kali pertemuan, sehingga pelatihan ini efektif digunakan untuk menurunkan kecemasan pada kelompok eksperimen.

Pelatih yang sesuai dengan metode pelatihan otogenik. Linden (2007), menyatakan bahwa pelatihan otogenik adalah pelatihan yang sifatnya selfhypnosis karena mempromosikan tentang kontrol diri dan kemandirian dari seorang terapis. Pelatih yang memberikan pelatihan otogenik adalah seseorang yang menguasai berbagai metode tentang hypnosis dan telah memiliki sertifikat resmi, sehingga pelatih merupakan orang yang sesuai untuk memberikan pelatihan otogenik. Pada pelatihan pertama, pelatih membangaun rapor dengan peserta pelatihan dengan memberikan beberapa permainan atau hiburan dalam proses hypnosis, sehingga para atlet dapat mempercayai pelatih dan pelatihan otogenik dapat bekerja secara efektif untuk menurunkan kecemasan.

Keaktifan peserta. Berdasarkan observasi dan wawancara setelah pelatihan, keaktifan peserta sangat terlihat dari awal pelatihan. Peserta selalu menepati waktu yang telah disepakati dan antusias mengikuti pelatihan. Hal tersebut dimungkinkan karena para atlet sangat tertarik dengan materi yang berkaitan dengan penyegaran kondisi tubuh mereka. Pada pertemuan pertama tersebut para atlet sangat antusias dengan terus bertanya tentang berbagai hal yang berkaitan dengan pelatihan otogenik dan efeknya bagi tubuh mereka.
Kecemasan sebagai kepribadian (trait anxiety) didasarkan dalam pemikiran dan persepsi akan ketakutan menghadapi pertandingan (kognitif) dan peningkatan respon fisiologis (somatik). Atlet dapat memandang dunia sebagai suatu yang dapat diramalkan, dan perilaku individu turut berperan didalamnya dikarenakan penurunan kecemasan pada diri atlet tersebut. kesimpulan pada penelitian ini adalah adanya pengaruh pelatihan ototgenik terhadap penurunan kecemasan atlet bulutangkis.

\section{Simpulan}

Berdasarkan hasil penelitian dan pembahasan yang telah dipaparkan pada bab sebelumnya, hasil penelitian yang dilakukan terhadap kelompok eksperimen yang diberi perlakuan berupa pelatihan otogenik memiliki skor yang signifikan. Hal tersebut dapat dibuktikan dengan uji Wilcoxon, bahwa kelompok eksperimen memiliki skor signifikansi sebesar 0.027, apabila dibandingkan dengan nilai probalitas sebesar 0.05 maka nilai signifikansinya lebih kecil dari nilai probabilitas $(0.027<0.05)$.

Penurunan kecemasan yang terjadi pada atlet bulutangkis dapat dilihat dari perolehan hasil rata-rata kelompok eksperimen pada saat pretest 43 menjadi 34,67 pada saat posttest, sedangkan pada kelompok kontrol memiliki skor rata-rata saat pretest sebesar 43 dan saat posttest sebesar 43,33. Berdasarkan hasil tersebut, maka dapat ditarik kesimpulan bahwa pelatihan otogenik dapat menurunkan tingkat kecemasan pada atlet bulutangkis, sehingga hipotesis diterima.

\section{Saran}

Atlet diharapkan melakukan latihan otogenik secara rutin agar mampu menurunkan kecemasan yang menunjang kinerja olahraganya. Atlet dapat mengontrol keadaan dirinya dengan baik 
tanpa berdampak pada psikis dan biologisnya, sehingga atlet dapat melakukan perlombaan dengan baik tanpa disertai rasa takut, khawatir, dan cemas apabila sering melakukan latihan otogenik.

Selain itu, diharapkan pelatih beserta pengurus menerapkan pelatihan otogenik disela-sela latihan fisik dan teknik. Menggabungkan pelatihan otogenik dengan pelatihan mental lainnya akan sangat membantu agar lahitan mental dapat menyeluruh untuk aspek psikologis para atlet.
Sedangkan bagi peneliti selanjutnya diharapkan memperluas populasi dan menambah sampel penelitian. Peneliti selanjutnya hendaknya mempertimbangkan atau menambah variabel lain yang berhubungan dengan kecemasan olahraga. Dibutuhkan literatur yang lebih luas dan dalam apabila peneliti selanjutnya menggunakan pelatihan otogenik dan menguji apakah pelatihan ini efektif untuk subjek yang berbeda.

\section{Daftar Pustaka}

Adisasmito, L. (2007). Mental Juara Modal Atlet Berprestasi. Jakarta: Raja Grafindo Persada.

Amir, N. (2004). Pengembangan Instrumen Kecemasan Olahraga. Anima, 20 (1), 55-69. (Online). www.anima.ubaya.ac.id. Diakses 29 Oktober 2014.

Amir, N. (2012). Pengembangan Alat Ukur Kecemasan Olahraga. Jurnal Penelitian dan Evaluasi Pendidikan. $16 \quad$ (1). 116-137. (Online). http://journal.uny.ac.id. Diakses 22 Oktober 2014.

Cox, R. H. (2002). Sport Psychology: Concept and Applications. New York: Mc Graw-Hill Companies, Inc.

Dallowey, M. (1993). Concentration: Focus Your Mind, Power Your Game. Arizona: Optimal Performance Institute.
Gunarsa, S. D. (2008). Psikologi Olahraga Prestasi. Jakarta: Gunung Mulia.

Hidayat, Y. (2012). Modul Pelatihan, Intervensi Strategi Multiteknik Latihan Mental Untuk Pelatih Bulutangkis. Bandung: FPOK UPI.

Linden, W. (2007). The Autogenic Method of J. H. Schultz: Principles and Practice of Stress Management. New York: The Guildford Press.

Luthe, W. (2000). About a Methods of Autogenic Therapy. New York: Plenum.

Satiadarma, M. P. (2000). Dasar-Dasar Psikologi Olahraga. Jakarta: Pustaka Sinar Harapan.

Wann, D. J. (1997). Sport Psychology. New Jersey: Upper Saddle River. 